\title{
PROSES PENGKOTAAN DAN DIVERSIFIKASI LAHAN DI DESA NAMLEA
}

\author{
M Chairul Basrun Umanailo \\ Fakultas Pertanian dan Kehutanan Universitas Iqra Buru \\ chairulbasrun@gmail.com
}

\begin{abstract}
ABSTRAK
Proses urbanisasi di desa Namlea adalah konsekuensi dari perubahan status administrasi kabupaten Buru menjadi sebuah kabupaten. Fenomena perubahan mempengaruhi kehidupan sosial ekonomi masyarakat, seperti pola kekerabatan dan pola interaksi yang kemudian menggeser sifat homegen ke heterogen. Lokasi penelitian berfokus pada desa Namlea dengan mempertimbangkan factor perubahan struktur masyarakat dan pengurangan lahan pertanian. Jumlah informan yang diwawancarai terdiri dari petani, aparat desa, tokoh agama, tokoh masyarakat, dan pedagang. Teknik analisa data yang digunakan mengikuti konsep Miles dan Huberman dimana kegiatan dalam analisis data kualitatif dilakukan secara interaktif dan berkesinambungan. Hasil penelitian menunjukkan bahwa proses urbanisasi telah membawa dampak perubahan dalam pemenuhan kebutuhan hidup di mana orientasi kehidupan bergeser dari pertanian ke nonpertanian. Diversifikasi adalah dasar untuk meningkatkan nilai jual tanah dan keterbatasan produk pertanian sebagai akibat dari meningkatnya jumlah kebutuhan yang tidak diikuti oleh peningkatan sumber daya lahan dan produk pertanian.
\end{abstract}

Kata kunci: Namlea, Konversi, Petani, Desa, Buru

\begin{abstract}
The urbanization process in Namlea village is a consequence of the change in the administrative status of Buru regency into a district. The phenomenon of change affects the social-economic life of the community, such as kinship patterns and interaction patterns that shift from homogeneous to heterogeneous traits. The research location focuses on the village of Namlea in consideration of changes in community structure and the reduction of agricultural land. The number of informers interviewed was as many as farmers, village apparatus, religious figures, community leaders as well as traders. Analytical techniques used to follow the concept of Miles and Huberman where activities in the analysis of qualitative data are conducted interactively and continuously. The results showed that the urbanization process has brought about the impact of changes in the fulfilment of life needs in which life orientation shifts from agriculture to nonagricultural. Diversification is the basis for increasing the value of land selling and the limitation of agricultural products as a result of the increasing number of needs that are not followed by the improvement of land resources and agricultural products.
\end{abstract}

Keywords: Namlea, Conversion, Farmland, Village, Buru 


\section{PENDAHULUAN}

Pengembangan wilayah pedesaan dalam menunjang pembangunan daerah menjadi begitu penting dalam era desentralisasi, hampir sebagian besar wilayah pedesaan di Indonesia terus dikembangkan untuk pencapaian kesejahteraan masyarakat. Seiring dengan pencapaian masyarakat, hadirnya Desa Namlea sebagai salah satu desa pendukung terhadap Ibukota Kabupaten Buru maka akan lahir pula berbagai permasalahan sebagai konsekuensi logis dinamika pedesaan menjadi perkotaan, sehingga kondisi perubahan tersebut diharapkan mampu menjadi arah dan tujuan akhir pencapaian kesejahteraan masyarakat Desa Namlea.

Kecamatan Namlea merupakan Ibukota Kabupaten Buru terdiri dari 11 desa dan 9 dusun. Luas wilayah Kecamatan Namlea 226,55 Km. Penduduk Kecamatan Namlea menurut data Biro Pusat Statistik pada tahun 2018 adalah 34.326 jiwa (Data BPS, 2018). Sementara itu, desa Namlea merupakan salah satu desa di Kecamatan Namlea memiliki luas wilayah $12 \mathrm{Km}^{2}$ dan memiliki penduduk sebanyak 26,757 jiwa dengan pertumbuhan penduduk mencapai 6,26 per tahun.

Fenomena pengkotaan di Desa Namlea dapat kita pahami dengan ketersediaan sarana dan prasarana ekonomi serta infrastruktur pemerintahan yang keseluruhannya berada pada wilayah administrasi Desa Namlea, maka bisa dipahami pemanfaatan lahan akan lebih banyak didominasi oleh pembangunan infrastruktur serta perumahan rakyat. Kosentrasi penduduk di Desa Namlea sebagai akibat kosentrasi ekonomi, sosial dan pemerintahan membuat kebutuhan lahan pada setiap tahunnya terus meningkat, termasuk di dalamnya lahan pertanian yang kemudian banyak di konversi (alih fungsi) maupun didiversifikasikan untuk pemenuhan kebutuhan hidup sehari-hari.

Seiring dengan perkembangan, keberadaan serta eksistensi rumah tangga petani semakin terbatas. Peralihan lahan-lahan pertanian menjadi perumahan serta perkantoran dan juga perdagangan menjadikan petani semakin kesulitan, bahkan mulai terdesak untuk keluar dan mengembangkan pertanian pada lokasi yang jaraknya lebih jauh dari sebelumnya. Diversifikasi menjadi fenomena menarik ketika rumah tangga petani maupun pemilik lahan pertanian mulai melihat proses pengkotaan sebagai suatu kondisi yang menguntungkan. Berubahnya lahanlahan pertanian menjadi sarana ekonomi menjadi pertimbangan bagi mereka dalam penyesuaian terhadap perubahan yang terjadi di Desa Namlea.

Sudrajat (2018), dalam analisis penelitiannya menunjukkan petani Desa Tambakrejo menanam komoditas pertanian lahan sawah dibagi dalam 3 musim. Musim tanam 1 dan 2 mayoritas petani di Desa Tambakrejo mengusahakan produksi berupa tanaman padi. Sedangkan pada musim tanam 3 mayoritas petani Desa Tambakrejo mengusahakan lahannya untuk ditanami 


\section{Chairul Basrun Umanailo}

jenis komoditas pertanian palawija seperti jagung, tembakau, cabai, ketela, kacang tanah, melon, dan semangka. Sementara itu, Ndawa (Anon 2016) dari penelitiannya mendapatkan analisis perubahan luas lahan memberi pengaruh pada perubahan mata pencaharian petani dikarenakan penyerapan tenaga kerja harian di sektor pertanian menyusut seiring penyusutan luas lahan milik petani. Hal ini dibuktikan bahwa penurunan luas lahan sebesar $1 \mathrm{Ha}$ berdampak pada penurunan penggunaan tenaga kerja di sektor pertanian sebanyak 0,75 orang. Penyusutan tenaga kerja harian ini menyebabkan petani harus melakukan diversifikasi usahatani mereka. Mereka yang semula hanya menggantungkan hidup hanya dari bertani dan berternak saja sekarang selain bertani dan berternak mereka juga mengelola penginapan berupa bomestay dan kamar sewaan.

Kajian ini dilakukan berdasarkan preferensi proses pengkotaan di Desa Namlea serta diversifikasi lahan pertanian sebagai konsekuensi dari proses pengkotaan yang terjadi. Selain itu, kajian ini bertujuan untuk mendapatkan gambaran primer tentang pola diversifikasi serta dampak yang ditimbulkan terhadap rumah tangga petani maupun pemilik lahan pertanian di Desa Namlea

\section{METODE PENELITIAN}

Penelitian ini dilakukan di Desa Namlea, Kecamatan Namlea, Kabupaten Buru. Penentuan lokasi penelitian dilakukan secara sengaja (Gunawan 2014) dengan pertimbangan bahwa Desa Namlea dipilih sebagai lokasi penelitian karena memiliki persentase lahan pertanian yang besar dibandingkan dengan desa-desa lain di kecamatan Namlea. Jumlah informan yang akan diwawancarai sebanyak 25 orang yang diambil secara purposive (Rahtz, Warber, and Dieppe 2019) Dalam pertimbangan informan dianggap sebagai pihak terkait untuk mencapai tujuan penelitian (Whittemore, Chase, and Mandle 2001). Informan adalah aparatur desa, petani, tokoh agama, tokoh masyarakat dan pedagang. Data pada penelitian ini berasal dari sumber data primer dan data sekunder, dengan teknik pengumpulan data yang digunakan melalui observasi, wawancara, kuesioner dan studi pustaka(Hasan Afandi and Umanailo 2018). Pada langkah wawancara, peneliti melakukan wawancara menyeluruh dengan informan(Marshall 1996) dan melakukan pengamatan langsung terhadap semua kegiatan yang dilakukan oleh informan. Para peneliti juga mencari informasi pelengkap terkait dengan diversifikasi lahan pertanian di desa Namlea melalui diskusi dengan informan di lokasi (Qu and Dumay 2011). Wawancara dilakukan pada pukul 17.00-22.00 di mana para peneliti menyesuaikan waktu kerja dan seluruh informan. Teknik analisis yang digunakan dalam penelitian ini adalah analisis data kualitatif mengikuti konsep yang diusulkan Miles dan Huberman dan Spradley (Maxwell and Reybold 2015). Miles dan Huberman, mengemukakan bahwa kegiatan dalam analisis data 
kualitatif dilakukan secara interaktif dan berkelanjutan secara berkesinambungan pada setiap tahap penelitian sehingga dapat diselesaikan dan data sampai jenuh. Aktivitas dalam analisis data yaitu reduksi data, penyajian data, penarikan kesimpulan.

\section{KERANGKA TEORI/KONSEP}

\section{Proses Urbanisasi}

Dalam proses pembangunan kota, tidak dapat dilepaskan (Wang et al. 2018). Urbanisasi tidak hanya sentralisasi dan pertumbuhan populasi, tetapi juga melibatkan berbagai faktor komersial, terutama yang berkaitan dengan spesialisasi pekerjaan, pengembangan komunikasi, rekreasi, dan sebagainya (Peerzado, Magsi, and Sheikh 2018). Proses mengembangkan sebuah kota bukan hanya masalah populasi, tetapi jauh terkait dengan proses urbanisasi yang terjadi di suatu daerah dan mempengaruhi orang yang tinggal di wilayah tersebut. Meningkatnya pertumbuhan populasi dan aktivitas perkotaan meningkatkan timbulnya permintaan lahan. Ada kebutuhan akan hunian untuk mendorong kenaikan harga tanah. Urbanisasi dapat diartikan sebagai proses urbanisasi desa. Pengertian urbanisasi ini pun berbeda-beda, sesuai dengan interpretasi setiap orang yang berbeda-beda. Ir. Triatno Yudo Harjoko (2010) pengertian urbanisasi diartikan sebagai suatu proses perubahan masyarakat dan kawasan dalam suatu wilayah yang non-urban menjadi urban.

Secara spasial, hal ini dikatakan sebagai suatu proses diferensiasi dan spesialisasi pemanfaatan ruang dimana lokasi tertentu menerima bagian pemukim dan fasilitas yang tidak proporsional Shogo kayono dalam Abbas (2002) memberikan pengertian urbanisasi sebagai perpindahan dan pemusatan penduduk secara nyata yang memberi dampak dalam hubungannya dengan masyarakat baru yang dilatar belakangi oleh faktor sosial, ekonomi, politik dan budaya. Sementara Keban dalam Abbas (2002) berpendapat bahwa urbanisasi jangan hanya dalam konteks demografi saja karena urbanisasi mengandung pengertian yang multidimensional. Urbanisasi dari pendekatan demografis berarti sebagai suatu proses peningkatan konsentrasi penduduk diperkotaan sehingga proporsi penduduk yang tinggal menjadi meningkat yang biasanya secara sederhana konsentrasi tersebut diukur dari proporsi penduduk yang tinggal di perkotaan, kecepatan perubahan proporsi tersebut, dan perubahan jumlah pusat-pusat kota. Sedangkan urbanisasi menurut pendekatan ekonomi (Harahap 2013).

Urbanisasi adalah proses peningkatan proporsi orang yang tinggal di daerah perkotaan. Suatu proses yang didorong oleh perubahan struktural dalam masyarakat sehingga area negara pertama adalah daerah pedesaan dengan struktur mata pencaharian agraris dan sifat kehidupan masyarakat yang lambat lainnya atau melalui proses mendasar. Memperoleh sifat kehidupan 


\section{Chairul Basrun Umanailo}

kota. Proses urbanisasi dapat diartikan dalam dua pengertian. adalah perubahan penting dalam wilayah fisik dan sosial ekonomi wilayah karena percepatan kemajuan ekonomi, banyak orang yang pindah dari desa ke kota karena penarik kota, mis. peluang kerja (Jiménez et al. 2019). Secara umum proses urbanisasi akan terjadi terus menerus dan akan menghasilkan peningkatan ukuran suatu wilayah, dari desa ke kota, dari kota akan menjadi kota besar dan akhirnya akan menjadi Kota Perkotaan (Scott 1998). Dalam fase mega urban kota akan mengalami titik daya tarik, yang ketika pengembangan ini diteruskan kota akan menjadi seperti sampah, di mana fase kota dipenuhi dengan manusia dengan semua kegiatannya (Boncinelli, Bartolini, and Casini 2018). Urbanisasi adalah suatu proses yang didorong oleh perubahan struktural dalam masyarakat, sehingga daerah yang dulunya merupakan daerah pedesaan dengan struktur mata pencaharian agraris dan sifat kehidupan masyarakat secara bertahap atau Melalui proses tiba-tiba mendapatkan sifat kehidupan kota.

Urbanisasi dipicu adanya perbedaan pertumbuhan atau ketidakmerataan fasilitas-fasilitas dari pembangunan, khususnya antara daerah pedesaan dan perkotaan. Akibatnya, wilayah perkotaan menjadi magnet menarik bagi kaum urban untuk mencari pekerjaan. Dengan demikian, urbanisasi sejatinya merupakan suatu proses perubahan yang wajar dalam upaya meningkatkan kesejahteraan penduduk atau masyarakat. Perkembangan urbanisasi di Indonesia sendiri perlu diamati secara serius(Harahap 2013).

\section{Diversifikasi Lahan}

Yang dimaksud penggunaan lahan menurut Arsyad adalah setiap bentuk intervensi manusia (campur tangan) terhadap tanah guna memenuhi kebutuhan hidupnya baik material maupun spiritual (Damanhuri, Muspita, and Setyohadi 2017). Ada dua jenis penggunaan lahan besar yaitu pemanfaatan lahan pertanian dan pemanfaatan lahan non-pertanian. Pemanfaatan lahan yang optimal membutuhkan keterkaitan dengan karakteristik dan kualitas lahannya. Hal ini disebabkan oleh keterbatasan dalam pemanfaatan lahan yang sesuai dengan karakteristik dan kualitas tanah ketika dihubungkan dengan penggunaan lahan berkelanjutan (Umanailo 2019).

Diversifikasi hanya dapat diartikan sebagai kegiatan atau tindakan untuk membuat sesuatu menjadi lebih beragam atau tidak tetap hanya dalam satu jenis. Dalam dunia bisnis, diversifikasi ini sering diidentifikasikan dengan ungkapan "tidak menaruh telur dalam satu keranjang". Pemanfaatan lahan untuk pertanian memiliki sifat yang dinamis dan beragam sesuai dengan waktu, tempat, dan sejalan dengan perkembangan kebutuhan hidup yang tidak terbatas serta kemampuan untuk memanipulasi kondisi geologis tanah (Asfaw et al. 2017). Sifat dinamis ini mempengaruhi keberadaan pemanfaatan lahan untuk pertanian di suatu daerah. Pemanfaatan lahan seringkali berbeda atau bahkan bertentangan dengan potensi 
lahannya, sehingga bisa berdampak bencana. Di sektor pertanian, diversifikasi berarti mengalokasikan sumber daya pertanian untuk beberapa kegiatan lain yang menguntungkan secara ekonomi dan lingkungan. Sumber daya pertanian ini dapat berupa tanah pertanian, bangunan (kandang, lumbung, tanaman rumah, dll.), mesin pertanian, hingga input pertanian lainnya seperti pupuk.

Lahan merupakan unsur terpenting dalam pemenuhan kebutuhan dasar masyarakat. Kebutuhan pangan, sandang, dan papan masyarakat diperoleh dari hasil produksi lahanpertanian. Terlebih lagi adanya kebijakan pemerintah tertuang dalam Undangundang Nomor 7 Tahun 1996 tentang pangan, disebutkan bahwa ketahanan pangan adalah terpenuhinya pangan bagi setiap rumah tangga yang tercermin dari tersedianya pangan yang cukup baik jumlah maupun mutunya, aman, merata, dan terjangkau. Ini menunjukkan bahwa lahan merupakan sumberdaya alam yang sangat penting keberadaannya. Lahan dibedakan menjadi dua jenis menurut penggunaannya yaitu lahan pertanian dan bukan pertanian. Lahan pertanian dibedakan lagi menjadi lahan sawah dan bukan sawah. Lahan sawah meliputi sawah dengan pengairan irigasi, tadah hujan, pasang surut, dan lainsebagainya. Lahan bukan sawah meliputi tegal/kebun, ladang/huma, perkebunan, hutan rakyat, pengembalaan/rumput, sementara tidak diusahakan/lahan tidur, dan sebagainya. Lahan bukan pertanian terdiri dari rumah, bangunan dan halaman sekitarnya, hutan negara, rawa-rawa (tidak ditanami), jalan, sungai, danau, lahan tandus, dan lain sebagainya (Listia Dewi and Sarjana 2015).

Seiring dengan peningkatan jumlah penduduk dan perkembangan ekonomi, kebutuhan lahan untuk kegiatan nonpertanian cenderung terus meningkat. Kecenderungan tersebut menyebabkan alih fungsi lahan pertanian sulit dihindari (Iqbal dan Sumaryanto, 2007). Menurut Mc Gee (1985) wilayah pinggiran (periphery area) mempunyai chiri khas; sebagian besar penduduk bergantung pada sektor pertanian padi dengan kepemilikan lahan sempit, mengalami transformasi kegiatan dari pertanian ke berbagai kegiatan non pertanian, termasuk perdagangan dan industri. Konversi lahan pertanian akan berdampak luas. Dari aspek ekonomi akan mengurangi ketahanan pangan bagi produksi pertanian. Bagi masyarakat petani akan kehilangan pekerjaan sehingga daya beli menurun karena belum tentu petani dapat pekerjaan baru yang lebih baik (Dewi 2013). 


\section{Chairul Basrun Umanailo}

\section{PEMBAHASAN}

\section{Kondisi Sosial Ekonomi Masyarakat Desa Namlea}

Umumnya, orang-orang yang mendiami wilayah Desa Namlea merupakan ciri khas dari orangorang desa yang telah mengalami perubahan yang cepat dalam proses pembangunan yang berlangsung di Kabupaten Buru. Salah satu penyebab utama perubahan adalah lokasi Desa Namlea yang merupakan pusat ibukota Kabupaten Buru. Peningkatan populasi, meningkatkan tingkat pendidikan dan kebutuhan untuk membuka jenis pekerjaan di sektor jasa, membuat Desa Namlea lebih cepat perubahan untuk pembentukan sebuah kota kecil. Dalam perkembangannya, Desa Namlea dapat dilihat melalui indeks pertumbuhan dan perkembangan masyarakat pedesaan kita dapat mengamati dalam beberapa data berikut:

Tabel 1. Populasi

\begin{tabular}{cccc}
\hline Tahun & Perempuan & Pria & Jumlah \\
\hline 2015 & 12.772 & 13.119 & 25.891 \\
2016 & 12.891 & 13.218 & 26.109 \\
2017 & 13.120 & 13.404 & 26.524 \\
2018 & 13.214 & 13.512 & 26.726 \\
\hline \hline
\end{tabular}

Sumber: Monografi Desa Namlea, 2019

Tabel 1 menunjukkan peningkatan populasi Desa Namlea dalam 4 tahun terakhir. Peningkatan populasi yang paling terjadi di 2017 dari 415 penduduk. Rata-rata jumlah orang yang ditambahkan adalah 208 jiwa. Penambahan populasi meningkatkan tingkat kebutuhan untuk kebutuhan perumahan dan rumah tangga. Konsekuensi dari peningkatan populasi adalah perubahan di berbagai sektor kehidupan sosial ekonomi masyarakat desa. Perubahan dapat dilihat pada setiap dekade seperti yang dijelaskan dalam tabel berikut.

Tabel 2. Perubahan Sosio-Ekonomi

\begin{tabular}{clll}
\hline \hline \multicolumn{1}{c}{2000} & Tahun & \multicolumn{1}{c}{2019} \\
\hline Sosial & The terpusat penduduk migrasi & Perubahan pola & Peningkatan sistem \\
& dari Ambon, Sanana dan & komunikasi sosial seperti & kekerabatan masyarakat \\
& perpindahan penduduk dari & "Citizen Temu", Forum & melalui lembaga-lembaga \\
pulau pesisir Buru ke desa & Village. Perkembangan & sosial-budaya. Ada \\
Namlea. diferensiasi sosial & masyarakat desa semakin & perbaikan di tingkat \\
meningkat serta melemahnya & konsumtif. & pendidikan dengan sarana \\
& sistem sosial budaya & Pengembangan & dan prasarana sekolah dan \\
\hline
\end{tabular}

74 | SOSIOGLGBAL : Jurnal Pemikiran dan Penelitian Sosiologi, Vol. 4, №. I, Desember 2019 


\begin{tabular}{llll}
\hline & masyarakat desa & kelompok dari luar desa & kuliah meningkat \\
\hline Ekonomis & Meningkat dari fungsi lahan & Pembangunan & Peningkatan kebutuhan \\
& pertanian untuk perumahan dan & infrastruktur mengarah ke & konsumsi diikuti oleh \\
perdagangan & ekspansi pekerjaan & persaingan perdagangan \\
& terutama di sektor jasa & serta keterbatasan lahan \\
\hline \hline
\end{tabular}

Sumber: Pengolahan Data Primer, 2019

Tabel 2 menunjukkan perubahan sosial ekonomi masyarakat Desa Namlea, perubahan tersebut dibagi menjadi 3 dekade. Pada tahun 2000, menjadi awal perubahan, migrasi dari beberapa daerah di sekitar pulau Buru dan perubahan status administrasi mengubah struktur masyarakat dan menghilangkan dominasi masyarakat adat. Tahun 2010, perubahan infrastruktur dan ketersediaan sumber daya, tahun 2019 masyarakat meningkatkan tingkat pendidikan dan pengembangan dan eksplorasi dan sumber daya yang tersedia di Desa Namlea. Pergeseran dan perubahan yang terjadi berdampak pada seluruh masyarakat di desa Namlea dalam beberapa konteks yang berbeda sesuai dengan latar belakang serta orientasi yang mereka miliki dapat dilihat pada tabel di bawah ini:

Tabel 3. Pandangan Tentang Perubahan Sosial-Ekonomi

\begin{tabular}{|c|c|c|c|}
\hline & \multicolumn{3}{|c|}{ Tahun } \\
\hline & 2000 & 2010 & 2019 \\
\hline $\begin{array}{l}\text { Aparatur } \\
\text { desa }\end{array}$ & $\begin{array}{l}\text { Perubahan perilaku karena } \\
\text { meningkatnya populasi dari } \\
\text { luar desa menyebabkan } \\
\text { perubahan gaya hidup di } \\
\text { desa Namlea }\end{array}$ & $\begin{array}{l}\text { Polarisasi dalam masyarakat } \\
\text { berdasarkan budaya daerah } \\
\text { asal menjadi bagian penting } \\
\text { dalam asimilasi budaya }\end{array}$ & $\begin{array}{l}\text { Sistem Komunitas adalah } \\
\text { sistem kekerabatan, sosial dan } \\
\text { organisasi politik, lebih } \\
\text { kondusif. }\end{array}$ \\
\hline $\begin{array}{l}\text { Pemimpin } \\
\text { agama }\end{array}$ & $\begin{array}{l}\text { Diferensiasi sosial } \\
\text { meningkat dengan } \\
\text { meningkatnya populasi dari } \\
\text { luar }\end{array}$ & $\begin{array}{l}\text { Peningkatan sarana dan } \\
\text { prasarana ibadah mendorong } \\
\text { toleransi umat beragama }\end{array}$ & $\begin{array}{l}\text { Toleransi semakin } \\
\text { ditingkatkan dengan lahirnya } \\
\text { peraturan daerah kerukunan } \\
\text { umat beragama. }\end{array}$ \\
\hline $\begin{array}{l}\text { Pemimpin } \\
\text { komunitas }\end{array}$ & $\begin{array}{l}\text { Meningkatnya populasi telah } \\
\text { melemahkan budaya budaya } \\
\text { desa di mana pengaruh } \\
\text { budaya luar yang semakin } \\
\text { mempengaruhi masyarakat } \\
\text { di desa Namlea. }\end{array}$ & $\begin{array}{l}\text { masyarakat Namlea Village } \\
\text { semakin prural dan ada } \\
\text { peningkatan persaingan antara } \\
\text { budaya dari desa Namlea luar. }\end{array}$ & $\begin{array}{l}\text { masyarakat Namlea Village } \\
\text { semakin prural dan ada } \\
\text { peningkatan persaingan antara } \\
\text { budaya dari desa Namlea luar }\end{array}$ \\
\hline Pedagang & $\begin{array}{l}\text { Kebutuhan masyarakat } \\
\text { meningkat namun belum } \\
\text { didukung oleh fasilitas }\end{array}$ & $\begin{array}{l}\text { Semakin ditingkatkan fasilitas } \\
\text { perdagangan dengan } \\
\text { pengembangan pasar baru di }\end{array}$ & $\begin{array}{l}\text { Peningkatan bisnis dan } \\
\text { persaingan perdagangan } \\
\text { membuat harga pasar menjadi }\end{array}$ \\
\hline
\end{tabular}




$$
\begin{array}{ll}
\text { ekonomi yang memadai } & \text { daerah Lala. } \\
\text { dan infrastruktur. } & \text { labil sehingga pedagang } \\
& \text { semakin sulit untuk } \\
& \text { mengembangkan bisnis } \\
& \text { mereka. }
\end{array}
$$

\section{Sumber: Pengolahan Data Primer, 2019}

Pada Tabel 3, ada beberapa pandangan yang memiliki optimisme dan beberapa masih berpikir bahwa pembangunan dan perubahan yang dilakukan belum sepenuhnya berdampak positif. Di desa segmen aparat, optimisme terlihat dari peningkatan jumlah penduduk dan perubahan sosial ekonomi masyarakat yang dianggap semakin kondusif dan mampu menciptakan toleransi multikultural dan kekeluargaan. tokoh masyarakat memiliki pandangan optimis ketika perubahan masyarakat dapat didukung oleh Pemerintah melalui kebijakan dan peraturan. Sementara itu, segmen tokoh masyarakat prihatin tentang peningkatan populasi dan pengembangan yang dilakukan akan menghasilkan persaingan dan konflik di masyarakat.

Pengembangan Kabupaten Buru menjadi titik awal untuk perubahan Desa Namlea, perubahan struktur masyarakat, pembangunan infrastruktur dan manajemen sumber daya untuk mensegmentasi faktor utama perubahan sosial di Desa Namlea. Kondisi masyarakat yang berasal dari sifat-sifat homogen yang terdiri dari suku-suku asli dan penduduk sekitarnya ternyata heterogen karena kedatangan penduduk dari daerah sekitarnya dengan latar belakang sosial ekonomi yang berbeda. Fenomena ini menjadi dua kekuatan untuk pengembangan dan perubahan komunitas sosial ekonomi di Desa Namlea. Pada bagian pertama, heterogen mampu menjadi pendorong dalam penyediaan modal dan sumber daya pembangunan, sehingga peningkatan populasi berdampak pada peningkatan bisnis dan tenaga kerja.

\section{Diversifikasi Lahan di Desa Namlea}

Keberhasilan pembangunan pertanian, erat kaitannya dengan faktor geografis yaitu faktor fisik dan faktor non fisik. Faktor fisik, seperti tanah subur, iklim yang mendukung, dan sumber air yang memadai, sedangkan faktor non fisik adalah pada diri manusia sendiri dalam pemanfaatan sumber daya alam (antara lain pengolahan tanah, kelembagaan, dan Pengetahuan). Salah satu pemanfaatan lahan adalah fungsi lahan (konversi) tanah. Fenomena ini muncul sebagai kebutuhan dan permintaan akan tanah, baik dari sektor pertanian dan dari sektor pertanian serta dari sektor non-pertanian karena populasi dan kegiatan pembangunan. Berdasarkan hasil penyebaran kuesioner yang dilakukan pada 25 informan, penyebab perubahan penggunaan lahan pertanian dari pertimbangan ekonomi, di mana 84,6\% petani mengubah lahan karena alasan ekonomi. Sementara 15,4\% mengubah lahan pertanian bukan karena alasan ekonomi, penyebab lain karena tanah pertanian besar milik petani adalah warisan (sebesar 69,1\%) dan 
yang lainnya adalah orang yang membeli (sebesar 20,9\%). Sebagian besar petani mengubah pertanian mereka karena alasan ekonomi. Tanah yang dimiliki petani berasal dari warisan dan pembelian. Sebagai petani, keluarganya mendung sehingga para petani tidak berniat meninggalkan profesinya. Selain kebutuhan yang mendesak. Petani menjual pertanian mereka karena mereka mendapat tawaran dari komunitas migran dan tergoda oleh harga jual tanah yang tinggi.

\section{Proses Pengkotaan}

Pengembangan Kabupaten Buru menjadi titik awal untuk perubahan Desa Namlea, perubahan struktur masyarakat, pengembangan infrastruktur dan manajemen sumber daya untuk mensegmentasi faktor utama perubahan sosial di Desa Namlea. Kondisi masyarakat yang berasal dari sifat-sifat homogen yang terdiri dari suku-suku asli dan penduduk sekitarnya ternyata heterogen karena kedatangan penduduk dari daerah sekitarnya dengan latar belakang sosial ekonomi yang berbeda. Fenomena ini menjadi dua kekuatan untuk pengembangan dan perubahan komunitas sosial ekonomi di Desa Namlea (Avelino et al. 2019). Pada bagian pertama, heterogen mampu menjadi pendorong dalam penyediaan modal dan sumber daya pembangunan sehingga peningkatan populasi berdampak pada peningkatan bisnis dan tenaga kerja. Pembangunan pada dasarnya adalah proses perubahan sosial ekonomi yang bertujuan untuk meningkatkan standar hidup, kualitas hidup dan manfaat manusia yang dilakukan secara sengaja dengan tindakan. Persepsi publik tentang proses urbanisasi adalah persentase tertinggi dari perubahan struktur komunitas.

Masyarakat melihat perubahan struktur untuk menyelamatkan masalah seperti itu sebagai konflik kepentingan kelompok, referensi sumber daya hingga persaingan antar suku ketika kondisi pertumbuhan populasi lebih tinggi tetapi tidak diikuti oleh penambahan sumber daya ekonomi. Proses urbanisasi terjadi dalam perubahan struktur komunitas serta perubahan dalam pola interaksi di mana elemen pembuatan membuat keseragaman menjadi heterogen dan masyarakat semakin terpolarisasi dalam kelompok kepentingan dan persamaan area asal. Pola interaksi menyebabkan orientasi untuk memenuhi kebutuhan tidak didasarkan pada sumber daya alam tetapi dikembangkan di sektor bisnis yang tidak terkait langsung dengan alam, sehingga komunitas Desa Namlea tidak lagi menjadi struktur komunitas yang memiliki Ketergantungan pada alam sebagai kondisi sebuah desa. Secara administratif, Desa Namlea masih berupa desa tetapi pada kehidupan sosial Desa Namlea telah menjadi kota kecil dengan pertumbuhan yang masih acak. Konsekuensi logis dari proses urbanisasi adalah salah satunya pada pemanfaatan lahan (Irawan 2016). Tanah menjadi sesuatu yang memiliki nilai tinggi 


\section{Chairul Basrun Umanailo}

karena kebutuhan manusia. Dampak urbanisasi membuat sebagian besar penduduk Desa Namlea mengonversi lahan untuk pemenuhan sehari-hari dan meningkatkan standar hidup.

Perubahan fungsi lahan menjadi dominan untuk pemrosesan sumber daya ekonomi menjadi efek domino dari pembangunan yang terjadi di Desa Namlea, pola pikir petani yang mengubah lahan menjadi perumahan, perkantoran dan pusat perdagangan semata-mata memengaruhi kebutuhan pasar untuk penyediaan lokasi tersebut. Perhitungan rasional untuk mengkonversi lahan adalah dampak dari perubahan masyarakat yang mengarah pada proses urbanisasi sehingga fungsi profesi menjadi fenomena yang bisa kita temui di Desa Namlea. Diversifikasi bukan peristiwa kebetulan, perubahan lahan menjadi pusat perdagangan dan kantor menjadi penginjilan bahwa orientasi penggunaan lahan tidak lagi pada sektor pertanian tetapi telah menggeser Sektor jasa dan perdagangan (Kiełbasa et al. 2018). Konsekuensi yang harus diterima adalah kenaikan harga jual produk pertanian serta ketersediaan bahan pokok yang bersumber dari pemanfaatan lahan pertanian.

\section{SIMPULAN}

Perubahan di Kabupaten Buru memiliki dampak langsung pada pengembangan Desa Namlea dimana masyarakat adat mulai bergeser karena meningkatnya kedatangan penduduk dari luar Desa Namlea. Konsekuensi logis dari kondisi tersebut menyebabkan perubahan di berbagai sektor kehidupan seperti ekonomi sosial yang berdampak pada pola interaksi dan pemenuhan kebutuhan. Perubahan struktur komunitas memudahkan proses urbanisasi di desa Namlea semakin cepat dengan dampak yang mengakibatkan perubahan dalam sistem kehidupan masyarakat. Diversifikasi tanah adalah dampak langsung dari proses urbanisasi sementara, orientasi diversifikasi lebih disebabkan oleh kebutuhan lahan dan kesempatan untuk meningkatkan kualitas hidup pemilik tanah dan petani. Peningkatan harga produk pertanian dan nilai jual tanah sebagai syarat berkurangnya produksi dan keterbatasan lahan.

\section{DAFTAR PUSTAKA}

Anon. (2016). "Perubahan Penggunaan Lahan Dan Faktor Yang Mempengaruhinya Di Kecamatan Gunungpati Kota Semarang." Majalah Geografi Indonesia.

Asfaw, Amogne, Belay Simane, Ali Hassen, and Amare Bantider. (2017). "Determinants of NonFarm Livelihood Diversification: Evidence from Rainfed-Dependent Smallholder Farmers in Northcentral Ethiopia (Woleka Sub-Basin)." Development Studies Research.

Avelino, Flor, Julia M. Wittmayer, Bonno Pel, Paul Weaver, Adina Dumitru, Alex Haxeltine, René Kemp, Michael S. Jørgensen, Tom Bauler, Saskia Ruijsink, and Tim O’Riordan. (2019). "Transformative Social Innovation and (Dis)Empowerment." Technological Forecasting and Social Change 145:195-206.

Boncinelli, Fabio, Fabio Bartolini, and Leonardo Casini. (2018). "Structural Factors of Labour Allocation for Farm Diversification Activities." Land Use Policy.

78 | SOSIOGLOBAL : Jurnal Pemikiran dan Penelitian Sasiologi, Vol. 4, No. I, Desember 2019 
Damanhuri, M. Muspita, and DPS Setyohadi. (2017). "Pengembangan Diversifikasi Usaha Tani Sebagai Penguatan Ekonomi Di Kabupaten Bojonegoro, Tulungagung, Dan Ponorogo.” Jurnal Cakrawala 11(1):33-47.

Dewi, Nurma Kumala. (2013). "Identifikasi Alih Fungsi Lahan Pertanian Dan Kondisi Sosial Ekonomi Masyarakat Daerah Pinggiran Di Kecamatan Gunungpati Kota Semarang." Wilayah Dan Lingkungan 1(2):175-88.

Gunawan, Imam. (2014). Metode Penelitian Kualitatif: Teori Dan Praktik.

Harahap, Fitri Ramdhani. 2013. "Dampak Urbanisasi Bagi Perkembangan Kota Di Indonesia." Society 1(1):35-45.

Hasan Afandi, Ahmad and M. Chairul Basrun Umanailo. (2018). "Watudakon Citizens 'Social Conflict on Joker Toll Road Development in 2017 in Kesamben District, Jombang Regency." The Journal of Social Sciences Research Special Is(5):656-61.

Irawan, Bambang. (2016). "Konversi Lahan Sawah: Potensi Dampak, Pola Pemanfaatannya, Dan Faktor Determinan.” Forum Penelitian Agro Ekonomi.

Jiménez, Alfredo, Guoliang Frank Jiang, Bent Petersen, and Jens Gammelgaard. (2019). "WithinCountry Religious Diversity and the Performance of Private Participation Infrastructure Projects." Journal of Business Research 95:13-25.

Kiełbasa, Barbara, Stefan Pietrzak, Barbro Ulén, Jan-Olof Drangert, and Karin Tonderski. (2018). "Sustainable Agriculture: The Study on Farmers' Perception and Practices Regarding Nutrient Management and Limiting Losses." Journal of W ater and Land Development.

Listia Dewi, Ida and I. Sarjana. (2015). "Faktor-Faktor Pendorong Alihfungsi Lahan Sawah Menjadi Lahan Non-Pertanian (Kasus: Subak Kerdung, Kecamatan Denpasar Selatan)." JURNAL MANAJEMEN AGRIBISNIS (Journal Of Agribusiness Management) 3(2):163-71.

Marshall, Martin N. (1996). "Sampling for Qualitative Research.” Family Practice.

Maxwell, Joseph A. and L. Earle Reybold. (2015). "Qualitative Research." in International Encyclopedia of the Social \& Behavioral Sciences: Second Edition.

Peerzado, Moula Bux, Habibullah Magsi, and Muhammad Javed Sheikh. (2018). "Land Use Conflicts and Urban Sprawl: Conversion of Agriculture Lands into Urbanization in Hyderabad, Pakistan." Journal of the Saudi Society of Agricultural Sciences.

Qu, Sandy Q. and John Dumay. (2011). “The Qualitative Research Interview.” Qualitative Research in Accounting and Management.

Rahtz, Emmylou, Sara L. Warber, and Paul Dieppe. (2019). "Understanding Public Perceptions of Healing: An Arts-Based Qualitative Study." Complementary Therapies in Medicine 45:25-32.

Scott, James C. (1998). “James C. Scott.” Foreign Affairs.

Sudrajat, Sudrajat. (2018). "Analisis Ketidakpastian Dalam Memanfaatkan Lahan Pertanian Di Desa Sukasari Kaler Kecamatan Argapura Majalengka.” Majalah Geografi Indonesia.

Umanailo, M. Chairul Basrun. (2019). "Consumption Diversification of Local Community." AGRISEP 18(1):61-72.

Wang, Jing, Yifan Lin, Anthony Glendinning, and Yueqing Xu. (2018). "Land-Use Changes and Land Policies Evolution in China's Urbanization Processes." Land Use Policy.

Whittemore, Robin, Susan K. Chase, and Carol Lynn Mandle. (2001). "Validity in Qualitative Research." Qualitative Health Research. 